\title{
The Conceptualisation of FEAR through Conceptual Metonymy and Metaphor in Jordanian Arabic
}

https://doi.org/10.33806/ijaes2000.19.2.1

\author{
Aseel Zibin and Jihad M. Hamdan \\ The University of Jordan, Jordan
}

\begin{abstract}
This study aims to examine the figurative devices used in Jordanian Arabic (JA) to conceptualise the emotion of FEAR. It investigates whether FEAR in JA can be conceptualised: (1) universally, on the basis of human embodied experiences; and (2) socioculturally, on the basis of culture specific schemas. The study adopts Conceptual Metaphor Theory (CMT) as its main theoretical framework to compare and contrast the similarities and/or differences in the conceptualisations of FEAR in both JA and English. Data are collected from two sources: namely, the comment section on Facebook pages of cinemas in Amman that show horror and thriller movies, and $12 \mathrm{JA}$ native speaker informants. Data analysis of the linguistic metonymical and metaphorical expressions shows that three figurative devices are used to conceptualise FEAR in JA: Conceptual metonymy, conceptual metaphor and conceptual metaphtonymy. Data analysis of the linguistic realisations in JA and English also demonstrate that both languages exhibit similarities and differences in the conceptualisations of FEAR. The similarities between the two languages are explained by relying on universal embodied cognition, whereas the differences are accounted for in terms of cultural filtering of general universal conceptualisations, reflecting experiences that are more common to a particular sociocultural group.
\end{abstract}

Keywords: cognitive linguistics, embodiment, metonymy, metaphor, semantics

\section{Introduction}

Traditionally, emotions have not been viewed as primary concepts in psychology, akin to language, thought and perception (Oatley and Kenkins1996). However, according to Kövecses (2003), the language of emotion is characterized by its high metaphoricity, which generates various metaphorical and metonymical expressions. In fact, current research has shown that not only do humans conceptualise emotions through metaphors and other figurative devices, but also, that the conceptual domain from which entities and characteristics are mapped onto the domain of emotion is none other than the human body. These findings obtained from studying emotion concepts had crucial implications for understanding embodied cognition (Maalej 2004; Crawford 2009; Ansah 2014). Conceptual embodiment is "the idea that the properties of certain categories are a consequence of the nature of the human biological capacities and of the experience of functioning in a physical and social environment" (Lakoff 1987:12). The mind is embodied in a way that maps the features of the human body and the surrounding environment. This mapping results in metaphorical expressions that 
reflect the fact that human conceptual systems exhibit similarities in conceptualising various abstract concepts (Lakoff and Johnson 1999).

In the past decade, several researchers (e.g. Maleej 2007; Kövecses 2015; Sharifian 2017, among others) have argued that there is a strong correlation between language, cognition and culture, especially with regard to metaphorical schemas and expressions. Such correlations have resulted in two viewpoints pertaining to whether emotions are: (1) universally conceptualised across cultures, or (2)tend to reflect language/culture specificity (Kövecses 2005; Ansah 2014). Proponents of the first view maintain that since emotions are grounded in universal human embodied cognitions, then naturally they can be found across cultures and languages. Conversely, supporters of the second view explain that because emotions are socioculturally structured, people in each culture share similar thought patterns and emotions whose conceptualisation is culture-specific. On the other hand, cross-cultural studies of the conceptualisation of emotions suggest that emotions can be conceptualised both universally, (based on embodied experiences), and socioculturally (based on culture specific schemas) (Kövecses, Palmer, and Dirven 2002; Maleej 2007; Simó 2011; Ansah 2014; Kövecses 2015). Supporters of this view explain that the reason emotions can be interpreted on both a universal and a culture-specific basis is that emotions are not only experienced as psychological states triggered by physiological events, but also by social events (Kövecses 2002). Since these findings were based on studies that examined both cross-cultural similarities and differences in conceptualising emotions, then more studies from other less explored languages and cultures can make important contributions to the understanding of the way emotions are conceptualised cross-culturally. This study aims to investigate the conceptualisation of FEAR in Jordanian Arabic, which may provide more evidence to support the argument that emotions can be conceptualised both universally and socioculturally. The data are analysed within the framework of Conceptual Metaphor Theory (CMT).

\section{Literature review}

\subsection{Conceptual Metaphor Theory (CMT)}

In Conceptual Metaphor Theory (CMT), a conceptual metaphor is construed as a systematic restructuring of a cognitive target domain, usually abstract, via a more concrete source domain. This is done by projecting semantic features, aspects, and /or entities of the source domain onto the target domain (Lakoff and Johnson 2003). Such a notion proposes that metaphor can be used to understand a more abstract concept via a less abstract or concrete concept. This mapping takes place since the source domain is easier to comprehend and can be a reference to reason about the target domain, which is more difficult to comprehend. Lakoff and Johnson (2003) argue that metaphors affect human mental perception of realities and so they are not language bound. In fact, Ponterotto (2014) suggests that we can use metaphors in everyday speech because they exist in our minds. Metaphorical and metonymical expressions are believed to be a good reflection of the human conceptual system since they are regarded as examples of our 
conceptualisation processes and organisation. In the CMT tradition, cognitive linguistic studies on the conceptualisation of emotion have been centred primarily on how the concepts are structured in a specific culture and across cultures through analysing the metaphorical and/or metonymical expressions that such concepts reflect. As such, CMT mainly aims to infer conceptual schemas based on linguistic expressions which are metaphorically and metonymically construed. The link that exists between our conceptual schemas and metaphorical expressions comes in the form of mappings between two cognitive domains. An example of a conceptual metaphor and a metaphorical expression that represents it is: FEAR IS A CONTAINER, reflected in the sentence, "They turned the lights out and sat in fear" (Kövecses 1990:70-73). Unlike conceptual metaphors, conceptual metonymies involve a single conceptual domain (Littlemore 2015). Metonymy aims to provide mental access to a conceptual domain via a part of the same domain, proposing that metonymy has a referential function through a STAND FOR RELATIONSHIP, e.g. a part stands for the whole or a part stands for another part within one conceptual domain (Kövecses 2000). An example of a metonymy is: AN INCREASE IN BODY HEAT STANDS FOR LOVE reflected in the sentence "I felt hot all over when I saw her" (Kövecses 2000). This theoretical framework is adopted while analysing the data of the current study. Note that CMT has been used as a theoretical framework by several researchers who worked on metaphor and metonymy (e.g. Kövecses 1990; Al-Harrasi 2003; Skorczynska and Deignan 2006; Maleej, 2007; Littlemore 2015; Zibin 2016a, 2016b, 2018; Haddad and Martínez 2019, among others).

\subsection{Studies on the conceptualisation of emotion through metaphors and metonymies}

While certain emotions have been analysed more than others (e.g. ANGER), numerous studies on the conceptualisation of other emotions through metaphors and metonymies can be found in the relevant literature (Matsuki 1995; Kövecses 1999; Glynn 2002; Maalej 2004; Sirvydé2006; Crawford 2009; Ansah 2014; Wilson and Lewandowska-Tomaszczyk 2017). In his study, Maalej (2004) examined ANGER metaphors in Tunisian Arabic (henceforth TA) and suggested that this emotion is conceptualised in TA as a physiological embodiment and a culturally specific embodiment, as well as a culturally tainted embodiment. This conceptualisation of ANGER is similar to that found in English where physiological embodiment produces linguistic expressions of ANGER, in which the part of the body employed for conceptualising the emotion is also physiologically influenced, e.g. body heat, redness in the face, etc. Conversely, culturally specific embodiment appears when parts of the body are culturally linked with ANGER. The last type of embodiment employs animal behaviour in addition to culturally ecological features, to taint ANGER expressions which are physiologically embodied. Maalej's (2004) work asserts that embodiment is an essential grounding for the metaphoric conceptualization of ANGER in TA. Maleej (2007) also investigated the conceptualisation of FEAR in TA from the perspective of cultural embodiment, suggesting that FEAR exhibits three kinds of this 
embodiment: (1) physiological, whereby the fear expression is used to depict a part of the body that is physiologically affected by fear, e.g. wijhuSfaarbilfij3a 'the colour drained from his face'/ 'his face went pale'(Maleej 2007: 93); (2) culturally motivated, whereby the fear expression describes a part of the body thought to be physiologically influenced by fear, and the basic level category is driven by culture, e.g. qalbi fi snaanibilxawf 'My heart jumped in my throat/out of my chest' (Maleej 2007: 96); and (3) culturally specific, whereby the fear expression schematically depicts a part of the body linked to the physiological change, e.g. wijhuqaTTanbilfij3a 'His face was white with fear'(Maleej 2007: 98).

In an earlier study, Kövecses (1990: 69) provided a comprehensive analysis of the conceptualisation of FEAR via metaphors and metonymies in English. He posits that central to the conceptualisation of FEAR in English is a dangerous situation that comes together with both behavioural and physiological reactions that eventually lead to fleeing. He explains that such a notion of fear is based on metonymy and represents the traditional understanding of this emotion in English. In this respect, Kövecses (1990: 70-73) suggests that the metonymies on which the conceptualisation of FEAR in English is based are: THE BEHAVIOURAL REACTIONS OF AN EMOTION STAND FOR THE EMOTION and THE PHYSIOLOGICAL EFFECTS OF AN EMOTION STAND FOR THE EMOTION. Examples of these two specific metonymical schemas are: "A DROP IN BODY TEMPERATURE STANDS FOR FEAR" reflected in the sentence "she was frozen in her boots" and "FLIGHT STANDS FOR FEAR" reflected in the sentence "he fled from persecution" (Kövecses 1990: 70-73). Despite the fact that conceptual metonymies in English represent the highly elaborated physiological aspects of FEAR, they are insufficient on their own to offer a full conceptual structure of FEAR. Apparently, conceptual metaphors are the primary way to provide a comprehensive conceptual structure of FEAR in English. The source domains employed in English to conceptualise FEAR include: FLUID IN A CONTAINER, CONTAINER, BEING, VICIOUS ENEMY, TORMENTOR, SUPERNATURAL BEING, OPPONENT, BURDEN, SUPERIOR, ILLNESS, NATURAL FORCE, OBJECT/SEED, and CONSTRUCTION. Examples of these conceptual metaphors are: FEAR IS A SUPERNATURAL BEING (GHOST) reflected in the sentence "she was haunted by the fear of death", FEAR IS A CONTAINER reflected in the sentence "they turned the lights out and sat in fear", FEAR IS A BURDEN reflected in the sentence "fear weighed heavily on them as they heard the bombers overhead", among others (Kövecses 1990: 70-73).

Ansah (2014) examined the conceptualisation of FEAR in Akan (a West African, Kwa language) and compared it to that in English, in order to find the similarities and differences between the two languages. The analysis of the two languages revealed similarities in the metaphorical and metonymical conceptualisation of FEAR. Such similarities lend support to the universal embodied cognition thesis. Nonetheless, the analysis also showed that languagespecific differences exist in these two languages. These differences were explained in terms of the role of culture in filtering the general universal conceptualisations of emotions, reflecting human experiences that are more prominent in a certain sociocultural group. In relation to metonymy, the 
conceptual metonymies in English used to refer to FEAR include: HAIR STRAIGHTENING OUT, INABILITY TO BREATHE, DROP IN BODY TEMPERATURE, INABILITY TO MOVE, SWEATING, DRYNESS OF MOUTH, BLOOD LEAVES FACE, and LAPSES IN HEARTBEAT. Conversely, no such metonymic expressions were found in Akan (Ansah 2014: 53). Pertaining to conceptual metaphors, English and Akan shared the following source domains: A BEING, THE HUMAN BODY, A CONTAINER, A SUPERNATURAL BEING, AN OPPONENT, and AN ILLNESS/DISEASE. On the other hand, the source domains TORMENTOR, BURDEN, ILLNESS, FLUID IN A CONTAINER and NATURAL FORCE appeared exclusively in English, whereas the source domain FIRE IN A CONTAINER appeared exclusively in Akan.

As demonstrated above, while the conceptualisation of FEAR has been investigated in languages such as English (Kövecses 1990), Akan (Ansah 2014), and Lithuanian (Sirvydé 2006), it has not been examined in Jordanian Arabic. Therefore, this study aims to contribute to the relevant literature on how such an emotion is conceptualised in $\mathrm{JA}^{(1)}$. It also aims to promote the debate on universal embodied cognition (Kövecses 2000, 2005; Maalej 2004, 2007). In particular, this study seeks answers to the following research questions:

1) What are the conceptual metonymies, metaphors and metaphtonymies used in JA to conceptualise FEAR?

2) What are the similarities and/or differences in the conceptualisation of FEAR in JA and English?

\section{Method}

\subsection{Data collection}

Due to the lack of an online corpus of JA, two sources were used: (1) the comment section available on Facebook pages of cinemas in Amman showing horror and thriller movies, i.e. Grand Cinema, Mecca Mall Cinema, and Taj Cinema; and (2) seven female and five male JA native speaker informants (cf. Zibin and Altakhaineh 2018). Source (1) was chosen on the belief that these pages may provide target metonymies and metaphors used to conceptualise FEAR in $\mathrm{JA}^{(2)}$.The comments were copied from the Facebook page for each horror movie. Replies on comments, where a Facebook user responded to a comment posted by another about a movie, e.g. blaming his/her friend for choosing a scary movie, were also copied. This suggests that some examples may seem elicited as they were taken out of context. The informants were recruited, via personal communication, to ensure that they are native speakers of urban JA. They were instructed to write expressions they use to express fear. They were also asked about the meaning of certain metonymical and metaphorical expressions that they used to express FEAR. The data from both sources were collected in 2018. Together, the collected data comprised approximately of 20,000 words. Specifically, the comments collected from Facebook comprised of $90 \%$ of the corpus (18,000 words), while those collected from JA native speaker informants constituted $10 \%$ (2,000 words). To avoid any potential influence from the informants' data, preference and style, the collected data from the informants are 
presented in a separate section. Note also that the data collected from the informants were re-checked by $10 \mathrm{JA}$ native speakers using an acceptability judgement task, and only those examples accepted by eight native speakers or more were included in this study.

This type of corpus is referred to in the relevant literature as a specialised corpus, where the data are collected to analyse a specific phenomenon (Deignan 2008). The data were analysed manually to obtain a better picture of how FEAR is conceptualised through metonymies and metaphors (cf. Ansah 2014) ${ }^{(3)}$.A specialised corpus can be analysed manually if its size is manageable (see Charteris-Black 2004). The manual analysis of the corpus revealed that the number of metonymical and metaphorical expressions collected from Facebook was 334, while those collected from the informants was 82 . It should be noted here that some metonymical and metaphorical expressions in both cases were repeated more than once.

\subsection{Conceptual metaphor and metonymy identification}

A bottom-up approach was used to extract the conceptual metaphors from linguistic evidence, whereby the linguistic data are the source of hypothesis formulation about mappings between the two conceptual domains in the metaphor (see Ansah 2014; Zibin in press). A systematic procedure to perform this extraction was proposed by Steen (2007). Consider example (1) as a case in point:

(1) 1-xo:f mta:rid-ha w mif Pa:dr-i tuhrub minnu the-fear following-her and no able-she escape from.it Lit.Fear is chasing her and she is not able to escape from it. 'Fear is chasing her and she cannot escape it.'

Metaphor Identification Procedure (MIP) was used to identify words that contain metaphors through differentiating between basic senses (related to the five senses or historical origin) and other senses. Thus, if a word has a sense which is not basic then it can be identified as a metaphorical expression (see Pragglejaz Group 2007: 3). A modified version of MIP, called MIPVU, was developed by Steen et al. (2010) to include the identification of directly expressed figurative language such as similes, e.g. fear is chasing her like an animal chases its prey. MIP, on the other hand, identifies linguistic expressions which are indirectly expressed, e.g. fear is chasing her. In spite of the emergence of MIPVU, many researchers still adopt MIP, rather than MIPVU (e.g. Ansah 2014; Zibin 2018). In the current study, MIP is followed rather than MIPVU, since the main objective of this study is to identify indirectly-expressed metonymical and metaphorical expressions, which are the main focus of MIP, rather than explicit or direct ones such as similes, which are identified under MIPVU (see Zibin in press).

In example (1), it seems that lxo:fmta:ridha 'fear is chasing her' has a nonbasic meaning, since fear does not literally chase people. This expression is used to depict fear as a dangerous animal or human. First, through using the word mta:ridha 'chasing her', cross-domain mappings between two domains can be 
established: DANGEROUS HUMAN/ANIMAL and FEAR. Second, the linguistic expression is transformed into a conceptual metaphor using a series of propositions. Third, a single proposition is generated and, together with the two concepts, i.e. DANGEROUS HUMAN/ANIMAL and FEAR, is used to obtain an open comparison between two propositions: SIM $\left\{\exists \mathrm{F} \exists \mathrm{a}[\mathrm{F} \text { (FEAR) }]_{\mathrm{t}}\right.$ [DANGEROUS HUMAN/ANIMAL (a) $]_{s}$. This open comparison means that there is similarity between state $F$ (FEAR) in the target domain and the entity $a$ (DANGEROUS HUMAN/ANIMAL) in the source domain. Fourth, a closed comparison can be generated from the open one that forms the analogy between FEAR and DANGEROUS HUMAN/ANIMAL. Fifth, the analogical structure is changed into a mapping structure between two domains (i.e. FEAR and DANGEROUS HUMAN/ANIMAL) with all the implicit similarities between them; thus, facilitating such inferences as: (1) FEAR chases humans like a DANGEROUS HUMAN/ANIMAL chases them; (2) the fearful human is like the chased prey that runs from the DANGEROUS HUMAN/ANIMAL, etc.

We followed Littlemore's (2015:127) procedure, adapted from Steen (2007), to identify metonymies, as in:
(2) wa??af
Palb-ha
$\min \quad$ 1-xo:f
Lit. Her heart stopped from fear.
from the-fear
'She was scared to death.'

First, it is evident that the expression wa??af ?albha 'her heart stopped beating' is used as a metonymical expression to refer to something connected through contiguity. Second, it is clear from the former expression that it is employed to reflect feeling scared. Third, the two entities in example (2) can be identified: FEAR and LAPSES IN HEARTBEAT. Fourth, one can infer that LAPSES IN HEARTBEAT is used to represent the emotion FEAR. Thus, the single conceptual domain is THE HUMAN BODY and everything linked to it, i.e. the physiological reaction. Finally, it can be concluded that example (2) is a metonymical expression used to represent the conceptual metonymy: LAPSES IN HEARTBEAT STAND FOR FEAR (cf. Kövecses 1990). The next section presents the data generated in the current study.

\section{Analysis of Facebook data \\ 4.1 Conceptual metonymies}

In line with Kövecses (1990: 70-73) and Ansah (2014:50), data analysis of the Facebook corpus shows that conceptual metonymies in JA can be classified under two metonymy schemas, namely (1) "THE PHYSIOLOGICAL EFFECTS OF AN EMOTION STAND FOR THE EMOTION" and (2) "THE BEHAVIOURAL REACTIONS OF AN EMOTION STAND FOR THE EMOTION”. However, data analysis of metonymical expressions of FEAR in JA shows that the first metonymy schema can be divided into two subtypes as follows (cf. Maleej 2007: 93): 


\section{A. THE REALISTIC PHYSIOLOGICAL EFFECTS OF AN EMOTION STAND FOR THE EMOTION \\ B. THE METAPHORICAL PHYSIOLOGICAL EFFECTS OF AN EMOTION STAND FOR THE EMOTION}

In the first type, the physiological effects that result from FEAR might be realistic. For instance, when someone feels afraid, he/she may experience changes in their heart rate. However, in the second type, the physiological effects of FEAR cannot be realistic, but rather metaphorical, so they result in metaphtonymies (cf. Ansah 2014), i.e. a metonymy within a metaphor, or a metaphor with a built-in metonymy (Goossens 1990). This type of interaction between metaphor and metonymy is discussed in section 4.3. The following examples from JA illustrate the first metonymy schema subtype, i.e. THE REALISTIC PHYSIOLOGICAL EFFECTS OF AN EMOTION STAND FOR THE EMOTION:

\section{CHANGE IN HEART RATE STANDS FOR FEAR}
(3) war?as ?alb-i lamma tilis min 1-xaza:ne fell.he heart-my when came out.he from the-wardrobe
Lit.My heart fell when he came out of the closet.
'I was scared to death when he came out of the wardrobe.'

HAIR STRAIGHTENING OUT STANDS FOR FEAR
(4) ya
hara:m-ik
$\min$
Palla, wa??af
JaSir ra:s-i
VOC pitiful-you from God, stood up
hair head-my
Lit.You don't fear God! My hair stood up.
'What's wrong with you? You made my hair stand on end!'

\section{DRYNESS IN MOUTH STANDS FOR FEAR}
(5) nifif
ri:?i
dried
saliva

Lit. My saliva dried.

'I was scared spitless.'

\section{DROP IN BODY TEMPERATURE STANDS FOR FEAR}
(6) tdzammad min 1-xo:f got-frozen. he from the-fear Lit.He got frozen from fear.
'He was scared stiff.'

PHYSICAL AGITATION STANDS FOR FEAR

(7) Pallah ysa:mh-ak xalleit-ini Parudz min 1-xo:f 
God forgive-you made-I shake.I from the-fear

Lit. May God forgive you; you made me shake from fear.

'God forgive you; I was so scared I was shaking.'

The second general metonymical schema is THE BEHAVIOURAL REACTIONS OF AN EMOTION STAND FOR THE EMOTION. Here, the behavioural reaction of FEAR stands for it, as illustrated in the following examples.

FLIGHT STANDS FOR FEAR

(8) fall-u $\min \quad$ l-xo:f

ran-they from the-fear

Lit. They ran from fear.

'They fled out of fear.'

INABILITY TO MOVE STANDS FOR FEAR

(9) dzmid-it

fi: $\quad$ mahall-i ${ }^{(4)}$

froze-I in place-my

Lit. I froze in my place.

'I was scared stiff.'

(10) nfalle:t $\min \quad$ l-xo:f

paralysed. I from the-fear

Lit. I got paralyzed from fear.

'My body was paralyzed by fear.'

INABILITY TO SPEAK/TO SPEAK NORMALLY STANDS FOR FEAR

$\begin{array}{ll}\text { (11) nrabat } & \text { lsa:n-i } \\ \text { tied } & \text { tongue-my }\end{array}$

Lit. My tongue became tied.

'I was so scared I got tongue-tied.'

INABILITY TO STAND UP STANDS FOR FEAR

(12) mifPa:dre Pawa?if $\min$ l-xo:f

no. can. I stand up. I from the-fear

Lit. I cannot stand up from fear.

'I was so scared I couldn't even stand up.'

INABILITY TO SLEEP STANDS FOR FEAR

(13) ma Srif-it Pana:m min l-xo:f

no know-I sleep-I from the-fear

Lit. I couldn't sleep from fear. 
'I was so scared I couldn't even sleep.'

INABILITY TO BREATHE STANDS FOR FEAR

(14) nPataS nafas-i min l-xo:f

stop breath-I from the-fear

Lit. I stopped breathing from fear.

'I was so scared I couldn't even breathe.'

INVOLUNTARY RELEASE OF BOWELS OR BLADDER STANDS FOR FEAR

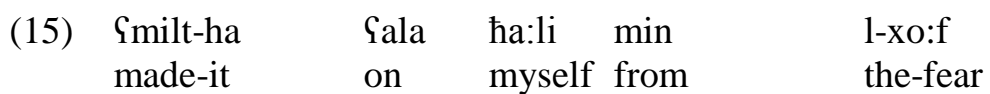

Lit. I made it on myself from fear.

'I was so scared I wet myself.'

Having discussed the metonymical expressions of FEAR used in JA, we move on to discuss the conceptual metaphors.

\subsection{Conceptual metaphors}

On the basis of data analysis, the main metaphors used in JA to conceptualise FEAR are listed below with illustrative examples:

FEAR IS A CONTAINER

$\begin{array}{llll}\text { ma: } & \text { tdall-ik } \quad \text { Ca:yji } & \text { fi: } & \text { l-xo:f } \\ \text { not } & \text { keep-you.F.SG living } & \text { in } & \text { the-fear }\end{array}$

Lit.Don't keep living in fear.

'Don't live in fear.'

FEAR IS A FLUID IN A CONTAINER
(17) 1-xo:f
mSabbi
Palb-ha
the-fear
filling
heart-her
Lit.Fear is filling her heart.
'Her heart is full of fear.'

FEAR IS A SUPERNATURAL BEING/INVISIBLE FORCE
(18) ltamas-it $\quad \min \quad$ l-xo:f possessed-I from the-fear
Lit. I got possessed by fear.
'I was possessed with fear.'

(19) 1-xo:f mrabit Pid-e: w ridzl-e: 
the-fear tying hands-his and legs-his

Lit.Fear is tying his hands and legs.

'He was tied down by fear.'

FEAR IS A DANGEROUS ANIMAL/HUMAN

(20) l-xo:f la:h?-u

the-fear follow-him

Lit.Fear is following him.

'Fear is stalking him.'

FEAR IS A SEED

(21) zaraS-u fi Plu:b-na l-xo:f

planted-they in hearts-ours the-fear

Lit.They planted fear in our hearts.

'They planted the seed of fear in our hearts.'

FEAR IS AN OPPONENT/ENEMY

$\begin{array}{lll}\text { tyallab } & \text { Sala } & \text { xo:f-u } \\ \text { conquered.he } & \text { on } & \text { fear-his }\end{array}$

Lit.He defeated his fear.

'He conquered his fear.'

FEAR IS AN ILLNESS

$\begin{array}{lll}\text { mrid-it } & \min & 1-x o: f \\ \text { got sick-I } & \text { from } & \text { the-fear }\end{array}$

Lit. I got sick from fear.

'I was sick with fear.'

FEAR IS A SUPERIOR
(24) 1-xo:f
saytar
Sale:-ha
the-fear
control
on-her
Lit.Fear has control over her.
'Fear dictates her actions.'

fear in JA.

The following section discusses the metaphtonymies used to conceptualise

\subsection{Conceptual metaphtonymies}

As mentioned in section 4.1, the second subtype of the metonymy schema, i.e. THE PHYSIOLOGICAL EFFECTS OF AN EMOTION STAND FOR THE EMOTION is THE METAPHORICAL PHYSIOLOGICAL EFFECTS OF AN EMOTION STAND FOR THE EMOTION. In this type, both metaphor and metonymy interact to conceptualise 
FEAR, yielding a metonymy with a built-in metaphor (Goossens 1990). This type could be the result of cultural beliefs; Jordanians use certain metonymical and metaphorical expressions related to FEAR to reflect beliefs about what happens to specific body parts as a result of such an emotion (cf. Maleej 2007). For example, some Jordanians tend to exaggerate by stating that if a woman is startled, she may lose her fertility. Or, if someone feels scared, his/her hair may turn grey. Some examples from JA that illustrate this subtype are provided below:

METAPHORICAL MISPLACEMENT OF HEART STANDS FOR FEAR

$\begin{array}{lll}\text { Palb-i } & \text { fi: } & \text { Pidzr-ayy } \\ \text { Heart-my } & \text { in } & \text { legs-my }\end{array}$

Lit. My heart is in my legs.

'I was shaking in my boots'.

METAPHORICAL WEAKNESS OF THE HEART STANDS FOR FEAR

$\begin{array}{llll}\text { yi: } & \text { ma: } & \text { PadGaf } & \text { Palb-u } \\ \text { INTERJ }^{(5)} & \text { VOC } & \text { weak } & \text { heart-his }\end{array}$

Lit. Oh how weak his heart is.

'Oh,you're so faint of heart!'

BLOOD DRYING METAPHORICALLY STANDS FOR FEAR ${ }^{(6)}$

$\begin{array}{llll}\text { nifif } & \text { damm-i } & \text { lamma } & \text { hdir-tu } \\ \text { dried } & \text { blood-my } & \text { when } & \text { saw-it }\end{array}$

Lit. My blood dried when I saw it (the movie).

'Watching that movie made my blood curdle.'

METAPHORICAL CHANGE IN HAIR COLOUR STANDS FOR FEAR

(28) wallah

swear.I.by. Allah

$\int a: b$

go.grey

JaSr-i

hair-my

Lit. I swear my hair became grey from fear.

'I was so scared my hair turned white.'

METAPHORICAL LOSS OF FERTILITY STANDS FOR FEAR

(29) PataG-tu xalaf-i

stopped-you.PL reproduction-my

Lit. You stopped my reproduction.

'I was so scared I became infertile.'

METAPHORICAL INABILITY TO SEE STANDS FOR FEAR

(30) nYama daww-i ${ }^{(7)}$ 
became.blind light-my

Lit. My light became blind.

'I was so scared I couldn't see straight.'

METAPHORICAL WEAKENING OF COMMON SENSE STANDS FOR FEAR

(31) ya: zalami xaff Ga?li min l-xo:f

VOC man decrease mind from the-fear

Lit. Oh man, my mind is weakened from fear.

'Man! I was scared crazy!'

Having presented data collected from Facebook, we move on to the present data collected from native speaker informants.

\section{Analysis of informants' data}

\subsection{Conceptual metonymies}

This section presents the metonymical expressions collected from the informants following the same order in the previous section. Starting with the first metonymy schema THE PHYSIOLOGICAL EFFECTS OF AN EMOTION STAND FOR THE EMOTION, more specifically the first subtype, i.e. THE REALISTIC PHYSIOLOGICAL EFFECTS OF AN EMOTION STAND FOR THE EMOTION, the following are some illustrative examples collected from the informants:

\section{CHANGE IN HEART RATE STANDS FOR FEAR}

(32) wa??a-Git Palb-i

fell-you heart-my

Lit. You made my heart fall.

'The way you scared me made my heart skip a beat.'

\section{DRYNESS IN MOUTH STANDS FOR FEAR}

$\begin{array}{llllll}\text { ya: } & \text { we:l-ak } & \text { min } & \text { Pallah } & \text { naffaf-it } & \text { ri:Pi } \\ \text { VOC } & \text { doom-you } & \text { from } & \text { God } & \text { dried-you } & \text { saliva }\end{array}$

Lit. May God ruin you; you dried my saliva.

'God damn you; you scared me spitless.'

FACE TURNING YELLOWISH STANDS FOR FEAR

(34) safran-it $\quad \min \quad$ lxo:f

turned.yellow-I from fear

Lit. I turned yellow from fear.

'I turned white I was so scared.'

Now we present examples of the second metonymic schema, namely, THE BEHAVIOURAL REACTIONS OF AN EMOTION STAND FOR THE EMOTION: 
INABILITY TO SPEAK/TO SPEAK NORMALLY STANDS FOR FEAR

$\begin{array}{llll}\text { sa:r } & \text { yta?ti? } & \text { min } & \text { 1-xo:f } \\ \text { became } & \text { stuttering } & \text { from } & \text { the-fear }\end{array}$

Lit. He started stuttering from fear.

'He was so scared he started stuttering.'

INABILITY TO SLEEP STANDS FOR FEAR

(36) mi $\quad$ Ga:rif yna:m $\quad$ min $\begin{aligned} & \text { l-xo:f } \\ & \text { from the-fear }\end{aligned}$
Lit. He cannot sleep from fear.
'He's so scared he can't sleep.'

INABILITY TO SIT STILL STANDS FOR FEAR
(37) 1-xo:f
mif mxali:
yisraf
yursud
the-fear
no making.him know.he
sit down

Lit. Fear is not making him know how to sit down.

'He's fidgety because he's scared.'

INABILITY TO STAND UP STANDS FOR FEAR

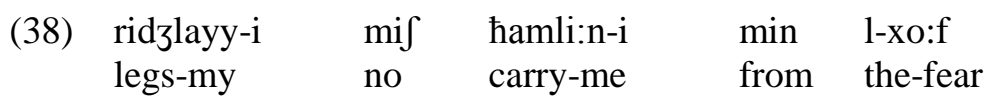

Lit. My legs cannot carry me from fear.

'I was so scared my legs turned to jelly.'

Next, we present the conceptual metaphors used to depict fear as reported by the informants.

\subsection{Conceptual metaphors}

FEAR IS A BIRD IN A CONTAINER

l-xo:f miafif $\quad$ fi: $\quad$ muxx-u
the-fear in $\quad$ brain-his
Lit. Fear is nesting in his brain.
'Fear is nesting in his brain.'

FEAR IS A KILLER
(40) 1-xo:f Pa:tl-u the-fear killing-him
Lit. Fear is killing him.
'Fear is killing him.'


Finally, the following section presents the second subtype of the metonymy schema THE PHYSIOLOGICAL EFFECTS OF AN EMOTION STAND FOR THE EMOTION, namely, THE METAPHORICAL PHYSIOLOGICAL EFFECTS OF AN EMOTION STAND FOR THE EMOTION.

\subsection{Conceptual metaphtonymies}

As discussed in section 4.3, metonymies with built-in metaphors representing THE METAPHORICAL PHYSIOLOGICAL EFFECTS OF AN EMOTION STAND FOR THE EMOTION can be found in JA, which yields metaphtonymies. The following are some illustrative examples of this subschema, for instance when one says:

\section{METAPHORICAL WEAKENING OF FAITH STANDS FOR FEAR}
$\begin{array}{llll}\text { xaff } & \text { Pi:ma:n-i } & \min & \text { l-xo:f } \\ \text { weakened } & \text { faith-my } & \text { from } & \text { the-fear }\end{array}$
Lit. My faith weakened from fear.
'Fear scared my faith out of me.'
'My faith weakened because of fear.'

In comparison with the metonymical and metaphorical expressions collected from Facebook, it can be observed that the data elicited from the informants were similar with the exception of the following conceptual metonymies and metaphors: FACE TURNING YELLOWISH STANDS FOR FEAR, METAPHORICAL WEAKENING OF FAITH STANDS FOR FEAR, INABILITY TO SIT QUIET STANDS FOR FEAR, FEAR IS A BIRD IN A CONTAINER, and FEAR IS A KILLER. Since each metonymical and metaphorical expression reflecting the above conceptual metonymies and metaphors was accepted by eight other native speakers (see section 3.1), it may not be feasible to claim that they reflect individual preferences.

Having presented the results, in the following section, a discussion of the metonymies, metaphors and metaphtonymies used in JA to conceptualise FEAR is provided.

\section{Discussion}

In section 4, it was shown how FEAR in JA can be conceptualised by three figurative devices, namely, conceptual metonymies, conceptual metaphors, and conceptual metaphtonymies. It seems that JA relies heavily on cognitive embodiment in the conceptualisation of FEAR. In both of the metonymy schemas (THE PHYSIOLOGICAL EFFECTS OF AN EMOTION STAND FOR THE EMOTION, and THE BEHAVIOURAL REACTIONS OF AN EMOTION STAND FOR THE EMOTION) and the two subtypes within the first schema (THE REALISTIC PHYSIOLOGICAL EFFECTS OF AN EMOTION STAND FOR THE EMOTION and (THE METAPHORICAL PHYSIOLOGICAL EFFECTS OF AN EMOTION STAND FOR THE EMOTION), many body parts are used to conceptualise FEAR. In the first metonymic schema, physiological embodiment is present, where FEAR is believed to be the direct 
cause for its own conceptualisation. That is to say, FEAR is the direct cause for lapses in heartbeat, changes in heart rate, dryness of the mouth, paleness of face, etc. (cf. Kövecses, 2000). In this metonymy subtype, the physiological effect is possibly realistic. For example, it has been shown scientifically that fear causes hair to stand on an end, i.e. piloerection, (Heathers, Fayn, Silvia, Tiliopoulos, and Goodwin 2018) and that it can result in a drop in body temperature, i.e. hypothermia (Oka 2015). Similarities in conceptualising FEAR can be found between JA and English. Below are examples of similar conceptual metonymies of FEAR based on realistic physiological states in JA and English.

1. INCREASE IN HEART RATE STANDS FOR FEAR

2. PHYSICAL AGITATION STANDS FOR FEAR

3. LAPSES IN HEART BEAT STANDS FOR FEAR

4. DRYNESS OF MOUTH STANDS FOR FEAR

5. DROP IN BODY TEMPERATURE STANDS FOR FEAR

6. HAIR STANDING ON END STANDS FOR FEAR

7. BLOOD LEAVES FACE/FACE TURNS YELLOWISH /WHITISH/ PALE ${ }^{(8)}$ STANDS FOR FEAR

Regarding the second metonymic schema, namely, THE BEHAVIOURAL REACTIONS OF AN EMOTION STAND FOR THE EMOTION, it seems that the behavioural reactions linked to FEAR such as FLIGHT are employed to stand for the emotion itself. Below are examples of similar conceptual metonymies of fear based on realistic behavioural reactions in JA and English.

1. FLIGHT STANDS FOR FEAR

2. INABILITY TO MOVE STANDS FOR FEAR

3. INABILITY TO SPEAK/TO SPEAK NORMALLY STANDS FOR FEAR

4. INVOLUNTARY RELEASE OF BOWELS OR BLADDER STANDS FOR FEAR

5. INABILITY TO BREATHE FOR FEAR

However, data analysis showed that other behavioural reactions were found in JA which stand for the emotion, i.e. INABILITY TO STAND UP STANDS FOR FEAR (example 12 and 38), INABILITY TO SLEEP STANDS FOR FEAR (example 13 and 36), INABILITY TO SIT STILL STANDS FOR FEAR (example 37). Although these behavioural reactions were not reported in previous studies on FEAR in English (see Kövecses 1990), one can argue that linguistic evidence reflecting some of these behavioural reactions can be found in English, e.g. "I woke up in the middle of the night and jolted up in bed, my eyes wide with fear" (Wilkerson 2017). Yet, such conceptual metonymical schemas seem to be more salient in JA as discussed later in this section.

We turn to the second subtype of the first metonymical schema, i.e. THE METAPHORICAL PHYSIOLOGICAL EFFECTS OF AN EMOTION STAND FOR THE EMOTION. Examples of this subtype are presented below. 


\section{METAPHORICAL MISPLACEMENT OF HEART STANDS FOR FEAR \\ 2. METAPHORICAL WEAKNESS OF THE HEART STANDS FOR FEAR \\ 3. BLOOD DRYING METAPHORICALLY STANDS FOR FEAR \\ 4. METAPHORICAL CHANGE IN HAIR COLOUR STANDS FOR FEAR \\ 5. METAPHORICAL LOSS OF FERTILITY STANDS FOR FEAR \\ 6. METAPHORICAL INABILITY TO SEE STANDS FOR FEAR \\ 7. METAPHORICAL WEAKENING OF COMMON SENSE STANDS FOR FEAR \\ 8. METAPHORICAL WEAKENING OF FAITH STANDS FOR FEAR}

In this conceptual schema, both metaphor and metonymy are employed to conceptualise FEAR in JA resulting in metaphtonymies. In example (26), repeated below as (42) for the reader's convenience, the body part ?alb 'heart' stands for the emotion it experiences, i.e. FEAR (metonymy), and the weakness of the heart is metaphorical not literal (metaphor), giving rise to a metaphtonymy:

(42) yi:

$\begin{array}{lll}\text { ma: } & \text { PadGaf } & \text { Palb-uh } \\ \text { VOC } & \text { weak } & \text { heart-his }\end{array}$

INTERJ VOC weak heart-his

Lit. Oh how weak his heart is.

'Oh, he's so faint of heart!'.

Since these physiological effects are not possible and were not attested in the English data (see Kövecses 1990), it can be suggested that they are grounded in the Jordanian culture and are as such culturally motivated (cf. Maleej 2007) ${ }^{(9)}$. That is, Jordanians may believe that FEAR can cause heart weakness, inability to reproduce, grey hair, weakening of faith, loss of common sense, etc. In fact, in Arab folklore in general and Jordanian folklore in particular, some people still believe that drinking water from a so-called anti-fear bowl, 'a bowl made of metal engraved with verses from the Quran' can help people who are startled by a scary scene or event or have horrific nightmares to feel calm and safe (Al-Rawabdeh 2014).Thus, it can be suggested that these non-real physiological or psychological effects of fear are grounded in Jordanian culture to the extent that some Jordanians believe that drinking from the anti-fear bowl is bound to cure them. In example (41), repeated below as (43), FEAR being the direct cause for weakened faith is rather interesting, since Jordanian society can be described as relatively religious. As such, one would expect and argue that fear may drive one to resort to God for comfort, rather than being a cause for weakened faith, when remarking:

xaff Pi:ma:n-i min l-xo:f
weakened faith-my from the-fear
Lit.My faith weakened from fear.
'Fear scared my faith out of me.'
'My faith weakened because of fear.'


Data analysis also revealed that several conceptual metaphors are used in JA to conceptualise fear. The list below shows the source domains that are shared in JA and English.
1. SUPERIOR
2. ILLNESS
3. CONTAINER
4. OPPONENT
5. SUPERNATURAL BEING
6. HUMAN OR ANIMAL
7. FLUID IN A CONTAINER
8. KILLER

In addition to the above conceptual metaphors shared in JA and English, data analysis revealed that JA exhibits another conceptual metaphor that was not reported in English, namely, FEAR IS A BIRD IN A CONTAINER. Linguistic evidence of this conceptual metaphor (see example 39) depicts fear as a bird nesting in the mind of the individual who experiences the emotion. This bird, however, may have negative connotations since as long as it stays in the person's head, he/she will never overcome his/her fear. To support this claim, another negative emotion that is conceptualised using this conceptual metaphor is DOUBT giving rise to the conceptual metaphor: DOUBT IS A BIRD IN A CONTAINER as in (44).

$\begin{array}{llll}\text { (44) l-xo:f miaflif } & \text { fi } & \text { muxx-u } \\ \text { the-fear nesting } & \text { in } & \text { brain-his } \\ \text { Lit.Fear is nesting in his brain. } & & \\ \text { 'Fear is nesting in his brain.' } & & \end{array}$

So far, it is evident that the data reported in the current study on the similarities and/or differences in the conceptualisations and other specific manifestations of common metonymical and metaphorical conceptualisations of FEAR in JA and English may provide more support to the embodiment thesis regarding the conceptualisations of emotions, FEAR, cross-culturally. This can be ascribed to the fact that such similarities pertaining to shared source domains and conceptual metonymies result from universal embodied cognition. For example, some general metaphorical and metonymical schemas are: EYES ARE CONTAINERS FOR THE EMOTIONS, EMOTIONS ARE BEINGS, and PHYSIOLOGICAL EFFECTS OF AN EMOTION STAND FOR THE EMOTION. These schemas generate language-specific conceptualisations which are driven by universally embodied cognition. As such, universal human experiences, including emotions such as FEAR, generate universal conceptual metaphors and metonymies (cf. Ansah 2014). So, regardless of being Arab or English, feeling afraid can cause changes to the heart rate, for example, giving rise to universal conceptual metonymies. 
On the other hand, the differences that appear across the language-specific conceptualizations could be accounted for via some cultural filtering of universally embodied cognition. Since many conceptualisations of FEAR present in JA, especially the second subtype of the first metonymic schema, are not attested in other cultures (e.g. METAPHORICAL CHANGE IN HAIR COLOUR STANDS FOR FEAR, METAPHORICAL WEAKENING OF FAITH STANDS FOR FEAR, etc.), it seems that conceptualisations of emotions can also yield culture specific expressions. In this regard, Kövecses (2005) argues that similarities and differences in conceptualising emotions cross-culturally take place in two primary areas: (1) the source domains through which a target domain is perceived; and (2) the elaborations in the conceptual similarities of shared conceptual metaphors. In the former, data analysis revealed that the majority of source domains used to conceptualise FEAR in English also exist in JA, as shown above. Even though the source domain KILLER was not reported in the studies on English, one can find linguistic evidence to reflect it, e.g. "This year, don't let fear kill your hustle before you even get moving" (Steimle 2016). JA also exhibits a source domain that was not reported in English, i.e. BIRD IN A CONTAINER.

Regarding the second area, even though both JA and English make metonymic references to parts of THE HUMAN BODY, language-specific realisations/elaborations show that THE HEART and THE STOMACH are the main ones which are employed metonymically to express FEAR in English (Kövecses 1990; Ansah2014). In JA, however, the two parts that are used mainly to express fear metonymically are THE HEART and THE LEGS. The latter manifests itself in several metonymic schemas, e.g. heart falling to legs (METAPHORICAL MISPLACEMENT OF HEART STANDS FOR FEAR), legs unable to carry one's weight (INABILITY TO STAND UP STANDS FOR FEAR), and legs and hands tied by a supernatural being/invisible force (FEAR IS A SUPERNATURAL BEING/INVISIBLE FORCE). THE STOMACH as apart that experiences the emotion of FEAR is not salient in JA compared to English. These differences in realisations/elaborations may point to some cultural filtering of universal/physiological embodied cognition, or a cultural link between a certain body part and a certain conceptualisation of an emotion which can be established yielding a fusion between culture and physiology (Maleej 2004; Ansah 2014).

Here, it can be proposed that the fact that people from the same community may share similar conceptualisations can lend support to the idea that cognition can be viewed as common in cultural groups, so human cognition is unquestionably influenced by culture (Sharifian 2008). Drawing on the above, it appears that FEAR metonymical, metaphorical and metaphtonymical expressions in JA support the idea that emotions can be both conceptualised universally based on human embodied experiences and socioculturally based on culture specific schemas (cf. Kövecses, Palmer, and Dirven 2002; Maleej 2004, 2007; Simó 2011; Ansah 2014; Kövecses 2015). 


\section{Conclusion}

This study investigated the conceptualisation of FEAR in JA and compared it to that found in English by adopting Conceptual Metaphor Theory (CMT) as its main theoretical framework. Data analysis reveals that FEAR is conceptualised in JA through three figurative devices: conceptual metonymy, conceptual metaphor and conceptual metaphtonymy. Both similarities and differences between JA and English in the conceptualisation of FEAR were revealed. This provides support to the universal cognitive embodiment thesis, where the similarities are based on universal physiological and/or behavioural states or reactions resulting from FEAR and being the direct cause for its conceptualisation. Conversely, differences have arisen from cultural beliefs that are grounded in a certain sociocultural group. It is recommended that other studies which examine other emotions in JA are needed to shed more light on the way universal cognitive embodiment can influence the human conceptualisation system.

Aseel Zibin

Department of English Language and Literature

University of Jordan

Jordan

aseel_zabin@hotmail.com

Jihad Hamdan

Department of English Language and Literature

University of Jordan

Jordan

jihaddan@yahoo.com

\section{Endnotes}

${ }^{1} \mathrm{JA}$ is a colloquial variety of Arabic spoken in Jordan, a country located in the Middle East. It includes three dialects: Bedouin, Rural and Urban. The three dialects share several lexical, morphological and syntactic features. However, the examples used throughout this study are illustrated in Urban JA, the native dialect of the informants and probably the most prestigious dialect among women, particularly youngsters in Amman, the capital of Jordan and many other cities.

${ }^{2}$ It should be noted that the authors cannot ensure that the comments posted on the horror and thriller movies on the target websites were written by Jordanians. Nor can they ensure that the comments were posted by the same individuals rather than being copied from other places (also see Zibin in press).

3 The discussion of whether the collected metonymical and metaphorical expressions are conventionalised or novel is beyond the scope of this study since they require more rigorous analysis to determine the degree of conventionality. 
${ }^{4}$ Note here that in JA, the inability to move because of fear is usually accompanied by drop in body temperature as indicated by 2 native speaker informants.

${ }^{5}$ INTERJ stands for Interjection.

${ }^{6}$ Blood drying here is different from the face turning yellowish; the former is not necessarily connected with the face.

${ }^{7}$ Another metaphorical expression with the same meaning is nSamu?ma:ri 'my moons (eyes) went blind'.

${ }^{8}$ Note that the term 'pale' for the face in English represents 'illness'.

${ }^{9}$ For studies that showed that role of culture in affecting individuals' linguistic behavior, see Altakhaineh, AL-Tkhayneh and Rahrouh (2019). 


\section{References}

Al-Harrasi, Abdulla. (2003). 'Ideological conceptual metaphors in ArabicEnglish translation of political discourse'. International Journal of Arabic English Studies, 4: 85-106.

Al-Rawabdeh, Rihan. (2014). 'The antifear bowl: The poor's weapon to fight fear and envy'. Retrieved from http://alrai.com/article/648400.html(Retrievedon 20th April 2019).

Altakhaineh, Abdel Rahman Mitib, Khawlah M. AL-Tkhayneh and Hanan N. Rahrouh.(2019). "The effect of the gender and culture of the IELTS examiner on the examinees' performance on the IELTS speaking test in the UAE context'.International Journal of Arabic-English Studies, 19(1): 3352.

Ansah, Gladys Nyarko. (2014). 'Culture in embodied cognition: Metaphorical/metonymic conceptualizations of FEAR in Akan and English'. Metaphor and Symbol, 29 (1): 44-58.

Charteris-Black, Jonathan. (2004). Corpus Approaches to Critical Metaphor Analysis. Basingstoke, Hampshire: Palgrave Macmillan.

Crawford, Elizabeth L. (2009). 'Conceptual metaphors of affect'.Emotion Review, 1 (2): 129-139.

Deignan, Alice. (2008). 'Corpus linguistics and metaphor'. In Raymond W. Gibbs (ed.) Cambridge Handbook of Metaphor and Thought, 280-294. Cambridge: Cambridge University Press.

Deignan, Alice. (2009). 'Searching for metaphorical patterns in corpora'. In Paul Baker (ed.), Contemporary Corpus Linguistics, 9-31. London: Continuum International Publishing Group.

Glynn, Dylan. (2002). 'Love and anger: The grammatical structure of conceptual metaphors'. Style, 36(3): 541-559.

Goossens, Louis. (1990). 'Metaphtonymy: The interaction of metaphor and metonymy in expressions for linguistic action'. Cognitive Linguistics, 1(3): 323-442.

Grand Cinemas Jordan.

https://www.facebook.com/GrandCinemasJordan/(Retrieved on $23^{\text {rd }}$ Aug 2018).

Haddad, Amal and Silvia Montero Martínez.(2019). 'Radiative Forcing' metaphor: An English-Arabic terminological and cultural case study. International Journal of Arabic-English Studies, 19(1): 139-158.

Heathers, James, Kirill Fayn, Paul J. Silvia, Niko Tiliopoulos and Matthew S. Goodwin. (2018). 'The voluntary control of piloerection'. Peer J, 6: e5292.

Kövecses, Zoltán, Gary Palmer and René Dirven.(2002). 'Language and emotion: The interplay of conceptualization with physiology and culture'. In René Dirven and Ralf Pörings (eds.), Metaphor and Metonymy in Comparison and Contrast, 133-159. Berlin: Mouton de Gruyter.

Kövecses, Zoltán. (1990). Emotion Concepts. New York, NY: Springer. 
Kövecses, Zoltán. (2000). Metaphor and Emotion. New York and Cambridge: Cambridge University Press.

Kövecses, Zoltán. (2003). Metaphor and Emotion: Language, Culture, and Body in Human Feeling. Cambridge: Cambridge University Press.

Kövecses, Zoltán. (2005). Metaphor in Culture: Universality and Variation. Cambridge: Cambridge University Press.

Kövecses, Zoltán. (2015). Where Metaphors Come from: Reconsidering Context in Metaphor. Oxford: Oxford University Press.

Lakoff, George and Mark Johnson. (1999). Philosophy in the Flesh: The Embodied Mind and its Challenge to Western Thought. New York: Basic Books.

Lakoff, George and Mark Johnson. (2003). Metaphors We Live By. 2nd ed. Chicago: University of Chicago Press.

Lakoff, George. (1987). Women, Fire, and Dangerous Things: What Categories Reveal about the Mind. Chicago, IL: University of Chicago Press.

Littlemore, Janette. (2015). Metonymy. Cambridge: Cambridge University Press. Maalej, Zouhair. (2004). 'Figurative language in anger expression in TunisArabic: An extended view of embodiment'. Metaphor and Symbol, 19(1): $51-75$.

Maalej, Zouhair. (2007). 'The embodiment of fear expressions in Tunisian Arabic'. In Farzad Sharifian and Gary B. Palmer (eds.), Applied Cultural Linguistics: Implications for Second Language Learning and Intercultural Communication, 87-104. Amsterdam: John Benjamins.

Matsuki, Keiko. (1995). 'Metaphors of anger in Japanese1 Keiko Matsuki'. In John R. Taylor and Robert E. MacLaury (eds.), Language and the Cognitive Construal of the World, 137-153. Berlin: Mouton de Gruyter.

Mecca Mall Cinema.

https://www.facebook.com/cinemacityjo/(Retrieved on $12^{\text {th }}$ September 2018).

Oatley, Keith and Jennifer Jenkins.(1996). Understanding Emotions. Malden, MA: Blackwell.

Oka, Takakazu. (2015). 'Psychogenic fever: how psychological stress affects body temperature in the clinical population'. Temperature, 2(3): 368-378.

Ponterotto, Diane. (2014). Studies in Conceptual Metaphor Theory. 1st ed. Roma: Aracne.

Pragglejaz Group. (2007). 'MIP: A method for identifying metaphorically used words in discourse'. Metaphor and Symbol, 22(1): 1-39.

Sharifian, Farzad.(2008). Distributed, emergent cultural cognition, conceptualisation, and language. In Roslyn M. Frank, René Dirven, Tom Ziemke and Enrique Bernárdez (eds.), Body, Language, and Mind (vol. 2): Sociocultural Situatedness, 109-136. Berlin/New York: Mouton de Gruyter.

Sharifian, Farzad.(2017). Cultural Linguistics. Amsterdam/Philadelphia: John Benjamins.

Simó, Judit. (2011). 'Metaphors of blood in American English and Hungarian: A cross-linguistic corpus investigation'. Journal of Pragmatics, 43(12): 28972910. 
Skorczynska, Hanna and Alice Deignan.(2006). 'Readership and purpose in the choice of economics metaphors'. Metaphor and Symbol, 21(2): 87-104.

Smeile, Josh. (2016). '14 ways to conquer fear'. https://www.forbes.com/sites/joshsteimle/2016/01/04/14-ways-to-conquerfear/\#65d8e6df1c48 (Retrieved on 13 ${ }^{\text {th }}$ Feb 2019).

Steen, Gerard. (2007). 'Finding metaphor in discourse: Pragglejaz and beyond'. Cultura, Lenguaje y Representación/Culture, Language and Representation, 5:9-25.

Steen, Gerard, Aletta Dorst, J. Berenike Herrmann, Anna Kaal, Tina Krennmayr, and Trijntje Pasma. (2010). A Method for Linguistic Metaphor Identification: From MIP to MIPVU. Amsterdam: John Benjamins.

Taj Cinemas. https://www.facebook.com/TAJCinemasJo/ (Retrieved on $30^{\text {th }}$ September 2018).

Wilson, Paul A. and Barbara Lewandowska-Tomaszczyk. (2017). 'Pride in British English and Polish: A cultural-linguistic perspective'. In Farzad Sharifian (ed.), Advances in Cultural Linguistics, 247-288.Springer, Singapore.

Wilkerson, Madeline. (2017). 'The sleepless cycle of depression'. Huffpost. https://www.huffingtonpost.com/madeline-wilkerson/the-sleepless-cycleof-depression_b_9612578.html (Retrieved on14th Feb 2019).

Zibin, Aseel and Abdel Rahman M. S. Altakhaineh. (2018). 'An analysis of Arabic metaphorical and/or metonymical compounds: A cognitive linguistic approach'. Metaphor and the Social World, 8(1): 100-133.

Zibin, Aseel. (2016a). 'On the production of metaphors by Jordanian EFL learners: Acquisition and implications'. Topics in Linguistics, 17(2): 41-58.

Zibin, Aseel. (2016b). 'The comprehension of metaphorical expressions by Jordanian EFL learners'. SAGE Open, 6(2): 1-15.

Zibin, Aseel. (2018). 'The effect of the Arab Spring on the use of metaphor and metonymy in Jordanian economic discourse: A cognitive approach'. Review of Cognitive Linguistics, 16(1): 254-298.

Zibin, Aseel. (in press). 'A corpus-based study of metaphors used to describe Syrian refugees in Jordanian politico-economic discourse: A critical metaphor analysis approach'. Pragmatics and Society. Amsterdam: John Benjamins. 